\title{
Penyuluhan dan Pelatihan Pemanfaatan E-Commerce di Desa Cikakak Kecamatan Banjarharjo
}

\author{
Extention and Training of E-Commerce Account Creation in Cikakak Village, \\ Banjarharjo subdistrict
}

\author{
Agyztia Permana ${ }^{1}$, Robert Rizki Yono ${ }^{2}$, Ubaedillah ${ }^{3}$, Hendri Sucipto ${ }^{4}$ \\ ${ }^{1}$ Program Studi Teknik Informatika, Fakultas Teknik, Universitas Muhadi Setiabudi, Indonesia \\ ${ }^{2,3}$ Program Studi Pendidikan Bahasa dan Sastra Indonesia , Fakultas Keguruan dan Ilmu Pendidikan, \\ Universitas Muhadi Setiabudi, Indonesia \\ ${ }^{4}$ Program Studi Manajemen, Fakultas Ekonomi dan Bisnis, Universitas Muhadi Setiabudi, Indonesia \\ e-mail: ${ }^{1}$ a.premana@umus.ac.id, ${ }^{2}$ robertriskiyono@gmail.com, ${ }^{3}$ ubaedillah2@gmail.com, \\ hendrisucipto313@gmail.com
}

\begin{abstract}
Abstrak
Perkembangan teknologi saat ini mempermudah dan mempercepat proses pada penyelesaian suatu tugas. Dalam menjalankan usaha desa Cikakak masih dilakukan secara manual yaitu dengan menerima pesanan yang masuk. Hal ini dilakukan karena masih memiliki sedikit tenaga ahli dalam proses pengerjaannya selain itu karyawan yang ada belum menguasai teknologi informasi dan komunikasi. Oleh karenanya pengabdian masyarakat ini bermaksud untuk memberikan pengetahuan kepada anggota kelompok UMKM untuk melakukan pemasaran produk secara online dan meningkatkan ketrampilan para pekerja sehingga produk yang dihasilkan berkualitas. Tahapan dalam kegiatan pengabdian kepada masyarakat meliputi pertama, tim pelaksana kegiatan melakukan analisis situasi pada target yaitu mitra yang berlokasi di desa Cikakak. Kedua, setelah menganalisis situasi terdapat beberapa permasalahan yang dialami oleh mitra. Ketiga, tim merumuskan masalah dan mempersiapkan solusi terkait permasalahan mitra yaitu dengan memanfaatkan internet untuk mendukung kegiatan jual beli dan memanfaatkan penggunaan email untuk menunjang kegiatan para pelaku UMKM dengan tujuan untuk menumbuhkan perekonomian warga desa, kususnya desa Cikakak. Berdasarkan hasil pelaksanaan kegiatan yang telah dilakukan, dapat ditarik beberapa simpulan sebagai berikut yaitu warga desa cikakak, khususnya anggota kelompok UMKM mendapatkan pengetahuan tentang pemanfaatan teknologi informasi untuk menunjang efektifitas kerja atau kegiatan jual beli dan meningkatnya keterampilan dalam pemanfaatan jaringan internet, khususnya pemasaran produk secara on line.
\end{abstract}

Kata kunci-Penyuluhan dan Pelatihan, e-commerce, desa Cikakak.

\begin{abstract}
Current technological developments facilitate and speed up the process of completing a task. In running the business of Cikakak village is still done manually, namely by receiving incoming orders. This is done because it still has few experts in the process of work besides that existing employees have not mastered information and communication technology. Therefore, this community service intends to provide knowledge to msme group members to conduct online product marketing and improve the skills of workers so that the products produced are quality. The stages in community service activities include first, the implementation team of the activity conducts situation analysis on target, namely partners located in Cikakak village. Second, after analyzing the situation there are several problems experienced by partners. Third, the team formulated the problem and prepared solutions related to partner problems, namely by utilizing the internet to support buying and selling activities and utilizing the use of email to support the activities of MSMEs with the aim to grow the economy of villagers, especially Cikakak village. Based on the results of the implementation of activities that have been carried out, several
\end{abstract}

Submitted: Juli 2021, Accepted: Agustus 2021, Published: Agustus 2021

ISSN 2746-6345 (media online) 
conclusions can be drawn as follows, namely cikakak villagers, especially members of the MSME group to gain knowledge about the role of information technology to support the effectiveness of work or buying and selling activities and increasing skills in the utilization of internet networks, especially online product marketing.

Keyword-Extention and training, e-commerce, Cikakak village

\section{PENDAHULUAN}

Cikakak merupakan nama desa yang terletak di kecamatan Banjarharjo yang termasuk wilayah kabupaten Brebes bagian barat, provinsi Jawa Tengah. Desa Cikakak terletak di antara Jawa Tengah dan Jawa Barat, sehingga mereka memiliki dua budaya yaitu Jawa dan Sunda. Budaya Sunda sangat dominan seperti bahasa yang digunakan dalam berkomunikasi sehari-hari yaitu bahasa Sunda. Dengan adanya perkembangan teknologi sekarang ini masyarakat Cikakak tentunya berkeinginan seperti desa lainnya, khususnya dibidang Sumber Daya Manusia (SDM).

Pengembangan wawasan dan kemampuan dari SDM dapat meningkatkan kinerja keseluruhan komponen sistem. Perkembangan teknologi saat ini mempermudah dan mempercepat proses pada penyelesaian suatu tugas. Penguasaan pada perangkat teknologi menjadi syarat mutlak optimalisasi pemanfaatan teknologi ini (Ratih Wahyuningrum, 2018).

Merajut merupakan metode membuat kain, pakaian atau perlengkapan busana dari benang rajut. Tidak semua orang dapat membuat rajutan, karena dibutuhkan keterampilan khusus, ketelitian, dan ketekunan sehingga hasil rajutan menjadi berkualitas. Salah satu hasil dari merajut adalah tas rajut yang dibuat (Afuan et al., 2010). Untuk menampung hasil dari tas rajut yaitu usaha mikro kecil dan menengah (UMKM). Salah satu UMKM yang ada di Cikakak yaitu Ngasti Shop. Ngasti Shop adalah usaha individu yang didirikan oleh ibu Ngastiati sejak tahun 2012 yang memproduksi rajutan aneka tas dan dompet dari benang rajut dan jaring. Kekuatan hasil produksi UMKM desa adalah hasil produksi yang disebut sebagai teknik rajut jaring yang jarang diproduksi oleh pengrajin rajut lainnya. Sehingga perlu dilakukaknnya peningkatan karena Pada usaha UMKM mempunyai peranan strategis dan penting bagi pertumbuhan ekonomi (Handayani, T,. Sidiq, F,. \& Nur, 2021).

Dalam menjalankan usaha desa Cikakak masih dilakukan secara manual yaitu dengan menerima pesanan yang masuk. Hal ini dilakukan karena masih memiliki sedikit tenaga ahli dalam proses pengerjaannya selain itu karyawan yang ada belum menguasai teknologi informasi dan komunikasi (Yustiani \& Yustanto, 2017).

Dari pemaparan di atas, kami berniat menyelenggarakan Penyuluhan dan Pelatihan Pemanfaatan E-Commerce di Desa Cikakak. Oleh karenanya pengabdian masyarakat ini bermaksud untuk membentuk dan mengembangkan mandiri secara ekonomi dan sosial. Salah satunya dengan memberikan pengetahuan kepada anggota kelompok UMKM untuk melakukan pemasaran produk secara online dan meningkatkan ketrampilan para pekerja sehingga produk yang dihasilkan berkualitas.

Berdasarkan informasi yang diperoleh dari para sekretaris desa dan anggota kelompok UMKM, masalah yang dihadapi dapat diidentifikasikan yaitu bagaimanakah pemanfaatan internet dalam mendukung kegiatan jual beli desa Cikakak dan penggunaan email untuk menunjang kegiatan para pelaku UMKM desa Cikakak. Dengan adanya kegiatan pengabdian kepada masyarakat ini, diharapkan masyarakat desa Cikakak dapat memanfaatkan internet untuk mendukung kegiatan jual beli dan memanfaatkan penggunaan email untuk menunjang kegiatan para pelaku UMKM.

E-Commerce merupakan media transaksi dan promosi suatu produk. Saat ini banyak yang memanfaatkan teknologi internet, khusunya di sektor perekonomian. Kegiatan perekonomian saat ini banyak dilakukan dengan mendayagunakan media internet, salah satunya di bidang perdagangan. Lebih lanjut menurut (Wicaksono \& Sukapto, 2021) bahwa E-Commerce adalah berpotensi menciptakan teknopreneur dan meningkatkan pertumbuhan UMKM.

Menurut (Situmeang, 2018) Internet merupakan jaringan komputer yang berkembang pesat yang melahirkan model perdagangan elektronik. Selaras dengan pendapat Situmeang 
bahwa sektor bisnispun dapat memanfaatkan internet karena digunakan banyak orang, orang tersebut merupakan target untuk menjual barang yang telah diproduksinya.

Dari sisi fungsi lainnya, email juga sangat penting bagi anda yang menggunakan situs tertentu, misalnya anda tergabung dalam situs dan blog yang selalu memberikan sharing informasi kepada orang lain, setidaknya anda harus punya email terlebih dahulu agar nantinya anda bisa mudah untuk mengakses blog maupun situs yang spesifik tersebut. Lebih lanjut e-mail dapat bermanfaat untuk media komunikasi, pengiriman data, promosi, informasi, identitas di internet.

Salah satu kegunaan pentingnya pelatihan pemanfaatan jaringan LAN dan internet adalah dalam rangka mempersiapkan Sumber Daya Manusia, khususnya pelaku usaha menengah kecil agar handal dalam memberikan pelayanan kepada masyarakat. Alternatif yang dapat dilakukan yaitu dengan melakukan penyuluhan dan pelatihan secara rutin tentang pemanfaatan teknologi informasi dalam mendukung proses pelayanan perangkat desa/kelurahan. Oleh sebab itu, dilakukannya pelatihan sehingga diharapkan dapat menjadi langkah awal untuk mencapai tujuan yang lebih besar dari sekedar pelatihan semata.

\section{METODE PELAKSANAAN}

Sasaran dalam pengabdian ini yaitu warga desa Cikakak, khususnya kelompok usaha menengah kecil. Jarak dari Universitas Muhadi Setiabudi ke desa Cikakak yaitu kurang lebih 40 KM. Kegiatan ini dilaksanakan pada tanggal 26 September-26 Oktober 2020, dihadiri 35 peserta.

Tahapan dalam kegiatan pengabdian kepada masyarakat meliputi pertama, tim pelaksana kegiatan melakukan analisis situasi pada target yaitu mitra yang berlokasi di desa Cikakak. Kedua, setelah menganalisis situasi terdapat beberapa permasalahan yang dialami oleh mitra. Ketiga, tim merumuskan masalah dan mempersiapkan solusi terkait permasalahan mitra yaitu dengan memanfaatkan internet untuk mendukung kegiatan jual beli dan memanfaatkan penggunaan email untuk menunjang kegiatan para pelaku UMKM dengan tujuan untuk menumbuhkan perekonomian warga desa, kususnya desa Cikakak.

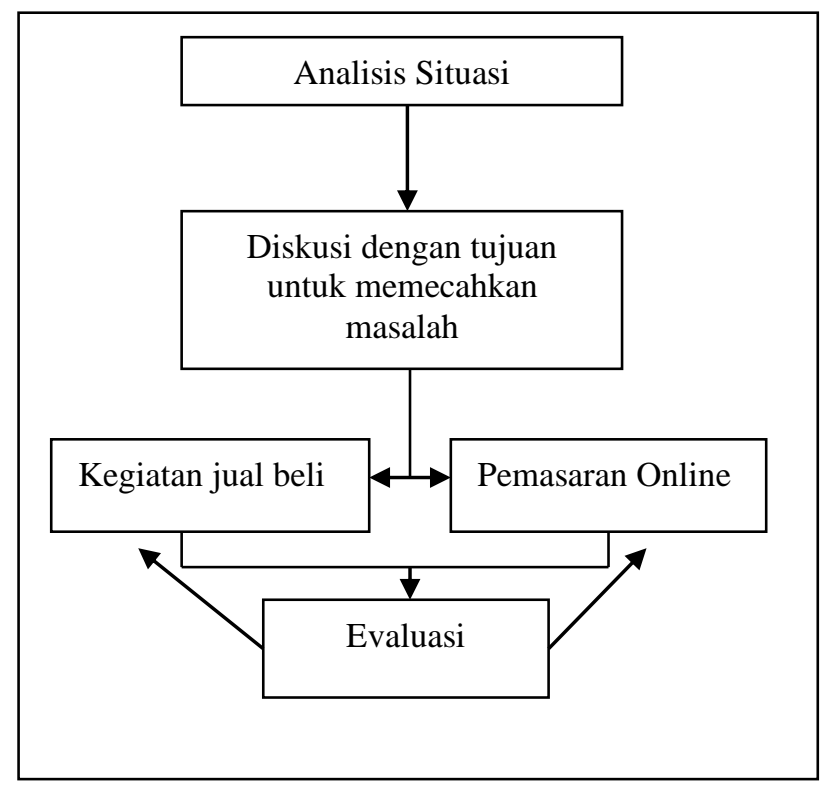

Gambar 1. Tahapan Kegiatan

Sebelum melaksanakan kegiatan pelatihan pemanfaatan jaringan internet kepada seluruh kelompok UMKM desa Cikakak, maka dilakukan beberapa proses seperti berikut ini.

1. Mencari referensi tentang pemanfaatan teknologi. 
2. Melakukan tanya jawab kepada beberapa anggota kelompok UMKM.

3. Menentukan waktu pelaksanaan dan lamanya kegiatan pengabdian.

4. Mempersiapkan materi yang akan disampaikan.

5. Melakukan uji coba pada peralatan pendukung pelatihan seperti switch, kabel Lan, modem, proyektor dan mikrofon.

\section{HASIL DAN PEMBAHASAN}

Kegiatan pengabdian kepada masyarakat ini dengan target yaitu anggota kelompok UMKM. Ketua tim pengabdian dibantu oleh anggota dalam melaksanakan kegiatan penyuluhan dan pelatihan secara langsung di desa Cikakak. Peserta sangat senang dan antusias mengikuti kegiatan ini, sehingga tim dengan baik mampu memberikan pengetahuan dan pemahaman kepada warga desa Cikakak, khususnya anggota kelompok UMKM tentang pemanfaatan teknologi informasi untuk menunjang efektifitas kerja atau kegiatan jual beli dan meningkatkan keterampilan dalam pemanfaatan jaringan internet, khususnya pemasaran produk secara on line. Selaras dengan (Febriyantoro \& Arisandi, 2018) bahwa penggunaan e-commerce dapat memperluas pemasaran produk. Lanjut menurut (Wibowo, 2016) bahwa produsen akan mampu bersaing jika mengimplementasikan teknologi ke dalam usahanya. Lebih lanjut, menurut (Atmaja \& Verawati, 2021) bahwa keuntungan dari e-commerce yaitu Produsen dapat memasarkan produknya di mana pun dan kapan pun, sehingga konsumen dapat membelinya dengan mudah.

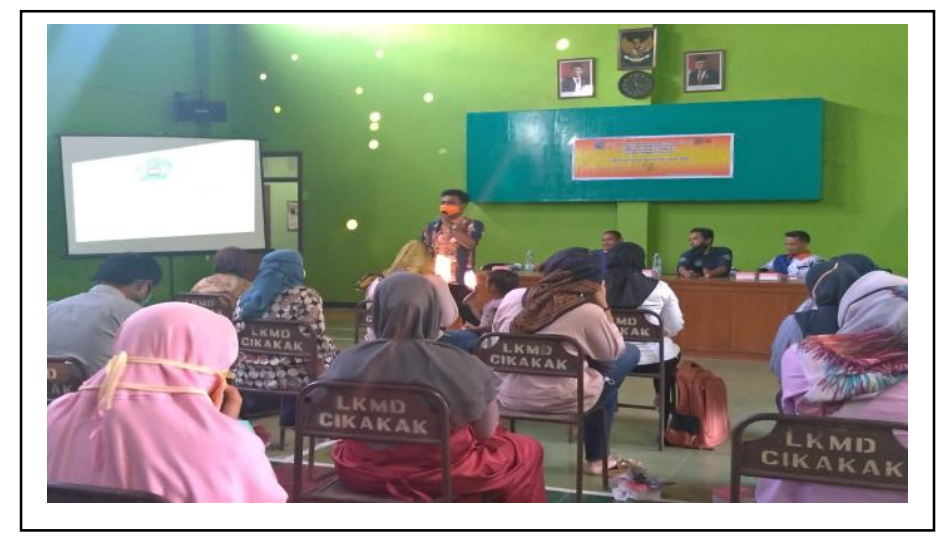

Gambar 1. Kegiatan Penyuluhan dan Pelatihan Pemanfaatan Internet E-Commerce

Dalam pelaksanaan kegiatan pelatihan ini, terdapat beberapa faktor pendukung dan penghambat. Faktor yang menjadi pendukung yakni besarnya minat dan antusiasme para peserta dalam mengikuti pelatihan sehingga kegiatan berlangsung dengan penuh semangat. Selaras dengan hasil pengabdian (Yono, 2020) bahwa peserta pelatihan sangat antusias mengikuti kegiatan pelatihan. Sedangkan faktor penghambatnya yakni keterbatasan waktu pelaksanaan yang disebabkan adanya keberagaman Sistem Operasi (Windows Xp, Win 7, dan Win 8) pada setiap komputer yang digunakan peserta selama pelatihan. Tentunya dengan adanya keberagaman system operasi ini dibutuhkan konfigurasi tersendiri pada tiap-tiap kelompok peserta berdasarkan jenis system operasi yang digunakan. 


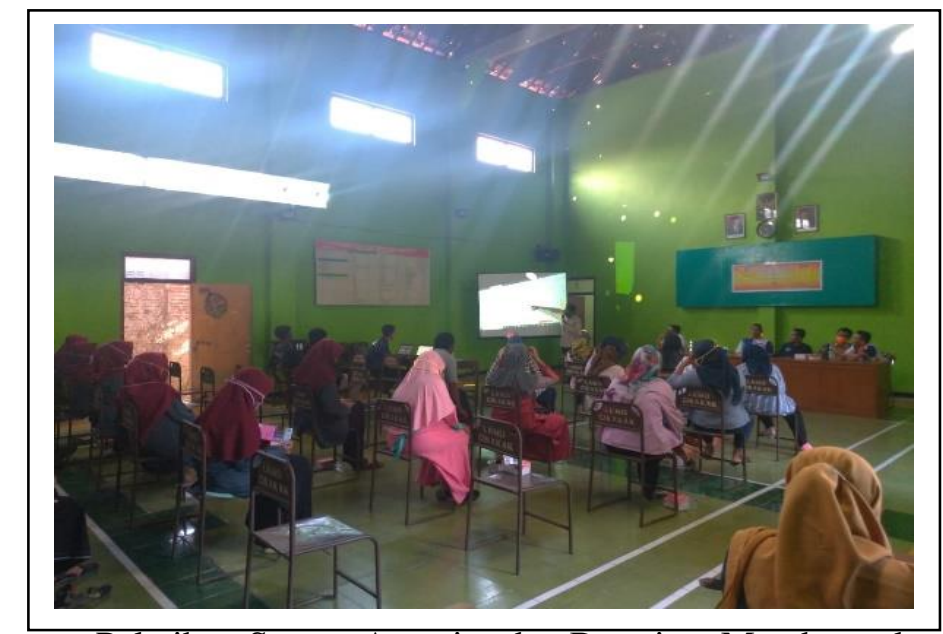

Gambar 2. Peserta Pelatihan Sangat Antusias dan Berminat Mendengarkan Materi yang disampaikan oleh TIM Pengabdian Masyarakat UMUS.

\section{KESIMPULAN}

Berdasarkan hasil pelaksanaan kegiatan yang telah dilakukan, dapat ditarik beberapa simpulan sebagai berikut yaitu warga desa cikakak, khususnya anggota kelompok UMKM mendapatkan pengetahuan tentang pemanfaatan teknologi informasi untuk menunjang efektifitas kerja atau kegiatan jual beli dan meningkatnya keterampilan dalam pemanfaatan jaringan internet, khususnya pemasaran produk secara on line.

\section{DAFTAR PUSTAKA}

Afuan, Soeparno, Mipa, D., \& Karangwangkal. (2010). Pengembangan Sistem Informasi Pendataan Laporan Kerja Praktek Mahasiswa Program Studi Teknik Informatika Unsoed ( Codeigniter Framework Used in Information System Development in Informatics Engineering Program Study of Unsoed ),. Jurnal Nasional UMP, 1, 39-44. http://jurnalnasional.ump.ac.id/index.php/JUITA/article/view/413/409

Atmaja, H. E., \& Verawati, D. M. (2021). Meningkatkan Minat Kewirausahaan Di Era Global Melalui E-Commerce. Jurnal Bisnis Dan Akuntansi Unsurya, 6(1), 57-66.

Febriyantoro, M. T., \& Arisandi, D. (2018). Pemanfaatan Digital Marketing Bagi Usaha Mikro, Kecil Dan Menengah Pada Era Masyarakat Ekonomi Asean. JMD: Jurnal Riset Manajemen \& Bisnis Dewantara, 1(2), 61-76. https://doi.org/10.26533/jmd.v1i2.175

Handayani, T,. Sidiq, F,. \& Nur, S. (2021). Upaya Pengembangan UMKM Melalui Pengelolaan Manajemen pada UMKM Konveksi Mutiara. Jurnal Abdi Masyarakat UMUS, 1(02), 4451.

Ratih Wahyuningrum. (2018). Analisis Strategi E-Marketing untuk Meningkatkan Minat Beli Online. ESENSI : Jurnal Managemen Bisnis, 21(3), 275-290.

Situmeang, R. R. (2018). Dampak Bisnis Online Dan Lapangan Pekerjaan Terhadap Peningkatan Pendapatan Masyarakat (Studi Kasus Jasa Bisnis Online Transportasi Grab Di Kota Medan). Ajie - Asian Journal of Innovation and Entrepreneurship - Asian Journal of Innovation and Entrepreneurship, 03(3), 319-335.

Wibowo, E. A. (2016). Pemanfaatan Teknologi E-Commerce Dalam Proses Bisnis. Equilibiria, 1(1), 95-108. http://journal.unrika.ac.id/index.php/equi/article/view/222

Wicaksono, I. B. A., \& Sukapto, P. (2021). Pengaruh online shopping experience produk fashion terhadap customer satisfaction dan repurchase intention The impact of online shopping experiences with fashion products on customer satisfaction and repurchase intention. Forum Ekonomi, 23(1), 20-28.

Yono, R. R. (2020). Pelatihan Membaca Puisi Bagi Siswa Madrasah Diniyah Ta'limul Huda Desa Randusanga Wetan. Cendekia: Jurnal Pengabdian Masyarakat, 2(2), 103. 
https://doi.org/10.32503/cendekia.v2i2.858

Yustiani, \& Yustanto. (2017). Peran Marketplace Sebagai Alternatif Bisnis Di Era Teknologi Informasi. KOMPUTA: JURNAL ILMIAH KOMPUTER DAN INFORMATIKA, 6(2). http://komputa.if.unikom.ac.id/jurnal/peran-marketplace-sebagai.3b 